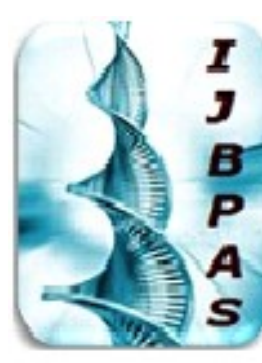

International Journal of Biology, Pharmacy and Allied Sciences (IJBPAS)

'A Bridge Betueen Caboratory and QRender'

WwW.ibpas.com

\title{
EFFECTS OF GENISTEIN ON ESTROGEN RECEPTOR AS ANTAGONIST DISRUPTING THE OVULATION IN FEMALE WISTAR RAT
}

\section{SHUKLA A, SHARMA R, MOHANTY S AND BALA K*}

Amity Institute of Biotechnology, Amity University Uttar Pradesh, Noida, (U.P.) India,

$$
201301
$$

*Corresponding Author: Bala K: E Mail: kbala@amity.edu

Received $3^{\text {rd }}$ Feb. 2020; Revised $3^{\text {rd }}$ March 2020; Accepted $18^{\text {th }}$ April 2020; Available online $1^{\text {st }}$ Sept. 2020 https://doi.org/10.31032/IJBPAS/2020/9.9.5207

\begin{abstract}
Progesterone and Estrogen are being used to synthesize Combined oral contraceptives (COCs) and serve as most convenient, safe, effective method of contraception. Due to their side effects in most women, herbal medicines have been proposed as alternatives to these contraceptive methods. The present study was aimed to evaluate the antifertility effects of Genistein (isolated from Glycine max), via in-silico and in vivo experimentation on female Rattusnorvergicus (Wistar albino rats). Genistein was docked with Estrogen Receptor of rats (ER $\alpha$ and ER $\beta)$. For, antagonist actions we compared ERA-4-[(2-\{4-[(1E)-1-(1H-indazol-5yl)-2-phenylbut-1-en-1-yl]phenoxy \} ethyl)amino]-N,N-dimethylbutanamide complex with ERA-genistein complex and ERB-(R,R)-5,11-cis-diethyl-5,6,11,12-tetrahydro-chrysene-2,8diol complex (PDB ID: 112J) with ERB-genistein complex. To further investigate the in vivo anti-fertility effects of Genistein and its correlation with serumestrogen, adult Rattus norvergicus (Wistar albino rats) was administered with 10, 20 and30mg Genistein/kg body weight dissolved in DMSO: PBS (1:4) vehicle for 15 days. Estrogen hormone level in the serum was estimated through ELISA. In-silico observation has shown that Genistein may act as antagonist for Estrogen Receptors. Serum estrogen level was found to be reduced, which can lead to disrupt ovulation. This shows that the Genistein might be working as antiovulatory agent by acting as a phytoestrogen.
\end{abstract}

Keyword: Genistein, estrogen, estrogen receptors, docking study, anti-ovulation, herbal contraceptive 


\section{INTRODUCTION}

Contraceptive pills are considered to be the most common and preferred method of contraception used by women compared to the other methods. These drugs are formulated by synthetic progesterone only or in combination with estrogen $[\mathbf{1 ,} 2]$. Synthetic steroidal contraceptives were initiated early in the twentieth century which was effective but along with these benefits there are many unwanted side effects associated with it such as obesity, nausea, breast and uterus cancer, disorders of cardiovascular system, and dysmenorrheal [3]. Research has shown the use of plants/phytochemicals for fertility regulation. Plant kingdom, therefore, holds a great promise for the invention of new and effective antifertility agents [4, 5]. Many studies have reported antizygotic, blastocytotoxic, anti-implantation, and abortifacient properties of many commonly used medicinal plants [6]. Usually foods containing phytoestrogens are considered safe for prolonged consistent usages on the daily basis but for women who are at the higher risk of developing the estrogen dependent cancers, prolonged daily usage of herbs and supplements containing phytoestrogens is not considered to be safe as they tend to alter the estrogen level in the women body making them more suspectable for inducing estrogen dependent cancer.
Genistein is a Phytoestrogen derived from soy (Glycine max), shown to possess estrogenic activities through its ability to bind to the estrogen receptor $\beta$ [7]. ERalpha (ERA) and ER-beta (ERB), are the two main types of estrogen receptor, which are activated by the sex hormone estrogen. In this study, we compared the docking scores of the ERA-Genistein, and ERBGenistein complex with their known antagonist fully understand the genistein's mechanism of action against ERA and ERB. For, antagonist actions we compared ERA-4-[(2-\{4-[(1E)-1-(1H-indazol-5-yl)-2phenylbut-1-en-1-yl]phenoxy\} ethyl)amino]$\mathrm{N}, \mathrm{N}$-dimethylbutanamide complex with ERA-genistein complex and ERB-(R,R)5,11-cis-diethyl-5,6,11,12-tetrahydrochrysene-2,8-diol complex (PDB ID: 112J) with ERB-genistein complex [8]. Furthermore, the antagonist effect was validated by hormonal analysis. The study aims to determine the effects of Genistein at different doses of $10 \mathrm{mg}, 20 \mathrm{mg}$ and 30 $\mathrm{mg} / \mathrm{kg}$ body weight/ day (dissolved in 1:4 DMSO: PBS) upto 15 days and also to correlate the alterations produced with the changes in the circulating levels of Estrogen.

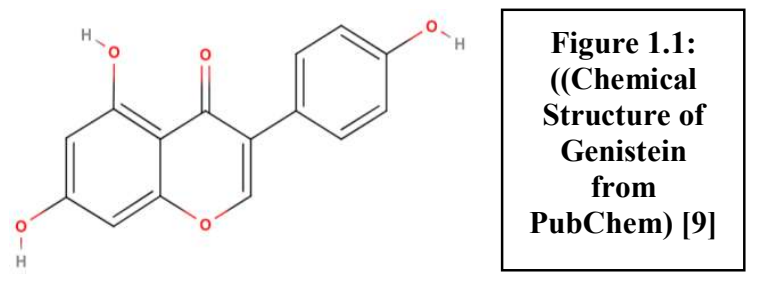




\section{MATERIAL AND METHODS}

\subsection{In-Silico Study}

\subsubsection{Protein Structure Preparation and} ligand Preparation

Missing Hydrogens were added to stabilize the PDB files. Potentially transposed heavy atoms in arginine, glutamine, and histidine side chains were corrected and optimization of the protein's hydrogen bond network by means of a systematic, cluster-based approach [10]. A restrained minimization was done that allows hydrogen atoms to be freely minimized while allowing for sufficient heavy-atom movement to relax strained bonds, angles, and clashes. The OPLS_2005 force field was used to minimize the Genistein structure. The structures were also desalted and stereoisomers were generated by retaining the specific chirality [11].

\subsection{In-Vivo Study}

\subsubsection{Hormonal Analysis}

Approximately 7-8 week old thirty female Wistar rats were housed and acclimated at approximately $24 \pm 2{ }^{\circ} \mathrm{C}$ temperature with $10 \mathrm{~h}: 14 \mathrm{~h}$ light $:$ dark cycle in the animal house of the Amity Institute of Pharmacology, Amity University Uttar Pradesh, Noida, India, following the guidelines of the Institutional Animal Ethics Committee (IAEC) formed under CPCSEA, Govt. of India. They were provided commercially available feed and water ad libitum. Commercially available
98\% pure HPLC grade Genistein powder purchased from Sigma Aldrich was used to prepare a dose containing $10 \mathrm{mg}, 20 \mathrm{mg}$ and $30 \mathrm{mgGenistein} \mathrm{/} \mathrm{kg}$ body weight / day, dissolved in 1: 4 Dimethyl sulfoxide (DMSO): Phosphate buffered saline (PBS). Thirty females rats, (6 ratsin each groups) were administered orally $10 \mathrm{mg}(\mathrm{gp}-3), 20$ $\mathrm{mg}(\mathrm{gp}-4)$ and $30 \mathrm{mg}(\mathrm{gp}-5)$ Genistein/kg body weight/day, dissolved in 1:4 Dimethyl sulfoxide (DMSO):Phosphate buffered saline (PBS) up to 15 days and remaining six received equal volume of vehicle (1: 4 , DMSO : PBS) alone (gp-2) for 15 days and last group of six rats were treated as negative control(gp-1). On $16^{\text {th }}$ day all the rats were sacrificed by cervical dislocation and their blood were collected into sterile collection vials by retro-orbital method. Sera were separated by appropriate technique and estimation of Estrogen (E2) hormone were done using appropriate ELISA assay kits developed by My BioSource, Inc., San Diego, USA.

\subsection{Statistical analysis}

Statistical analysis was carried out by oneway (ANOVA). Results were expressed as mean $\pm \mathrm{SE}$ and $\mathrm{P}$ values $\mathrm{p}<0.05$ were considered as significant.

\section{RESULTS}

\subsection{In-Silico Study}

Shown in Table 3.1.1.1 and Figure 3.1.1, 3.1.2, 3.1.3. 


\subsubsection{Molecular Docking}

Glide with XP calculations were carried out to calculate the Glide Score, with ERA \& ERB as receptors and Genistein, Estradiol, 4-[(2-\{4-[(1E)-1-(1H-indazol-5-yl)-2phenylbut-1-en-1-yl]phenoxy\} ethyl)amino]-N, N-dimethylbutanamide and (R,R)-5,11-cisdiethyl-5,6,11,12-tetrahydro-chrysene-2,8diol as ligands.The docking grid was constructed around the active site residues of the known antagonists (4-[(2-\{4-[(1E)-1(1H-indazol-5-yl)- 2-phenylbut-1-en-1-yl] phenoxy\} ethyl) amino] -N , N-dimethylbutanamide and (R,R)-5,11-cis-diethyl-5 ,6,11,12-tetrahydro -chrysene- 2,8-diol) and agonists (Estradiol), having dimensions as $15 * 15 * 15 \AA$ [12].

\subsection{In-Vivo Study}

\subsubsection{Effect of Genistein on Estrogen level}

It was observed that the estrogen level was increased in the treatment group -6in comparison with all the other groups. The decreased level of serum estrogen may disrupt the ovulation process by negative feedback, which will further block the secretions of FSH and LH (Figure 3.2.1).

Table 3.1.1: Comparison with known Antagonist

\begin{tabular}{|c|c|c|c|c|}
\hline S. No. & Receptor & Ligand & Mechanism & Docking Score \\
\hline 1 & Estrogen Receptor $\alpha$ & $\begin{array}{c}\text { 4-[(2-\{4-[(1E)-1-(1H-indazol-5-yl)-2-phenylbut- } \\
\text { 1-en-1-yl]phenoxy\} ethyl)amino]-N,N- } \\
\text { dimethylbutanamide } \\
\end{array}$ & Antagonist & -7.389 \\
\hline 2 & Estrogen Receptor $\alpha$ & Genistein & Antagonist & -8.692 \\
\hline 3 & $\begin{array}{c}\text { Estrogen Receptor } \beta \\
\text { Chain-A }\end{array}$ & $\begin{array}{c}\text { (R,R)-5,11-cis-diethyl-5,6,11,12-tetrahydro- } \\
\text { chrysene-2,8-diol }\end{array}$ & Antagonist & -8.263 \\
\hline 4 & $\begin{array}{c}\text { Estrogen Receptor } \beta \\
\text { Chain-A }\end{array}$ & Genistein & Antagonist & -9.11 \\
\hline 5 & $\begin{array}{c}\text { Estrogen Receptor } \beta \\
\text { Chain-B }\end{array}$ & $\begin{array}{c}\text { (R,R)-5,11-cis-diethyl-5,6,11,12-tetrahydro- } \\
\text { chrysene-2,8-diol }\end{array}$ & Antagonist & -7.242 \\
\hline 6 & $\begin{array}{l}\text { Estrogen Receptor } \beta \\
\text { Chain-B }\end{array}$ & Genistein & Antagonist & -9.073 \\
\hline
\end{tabular}
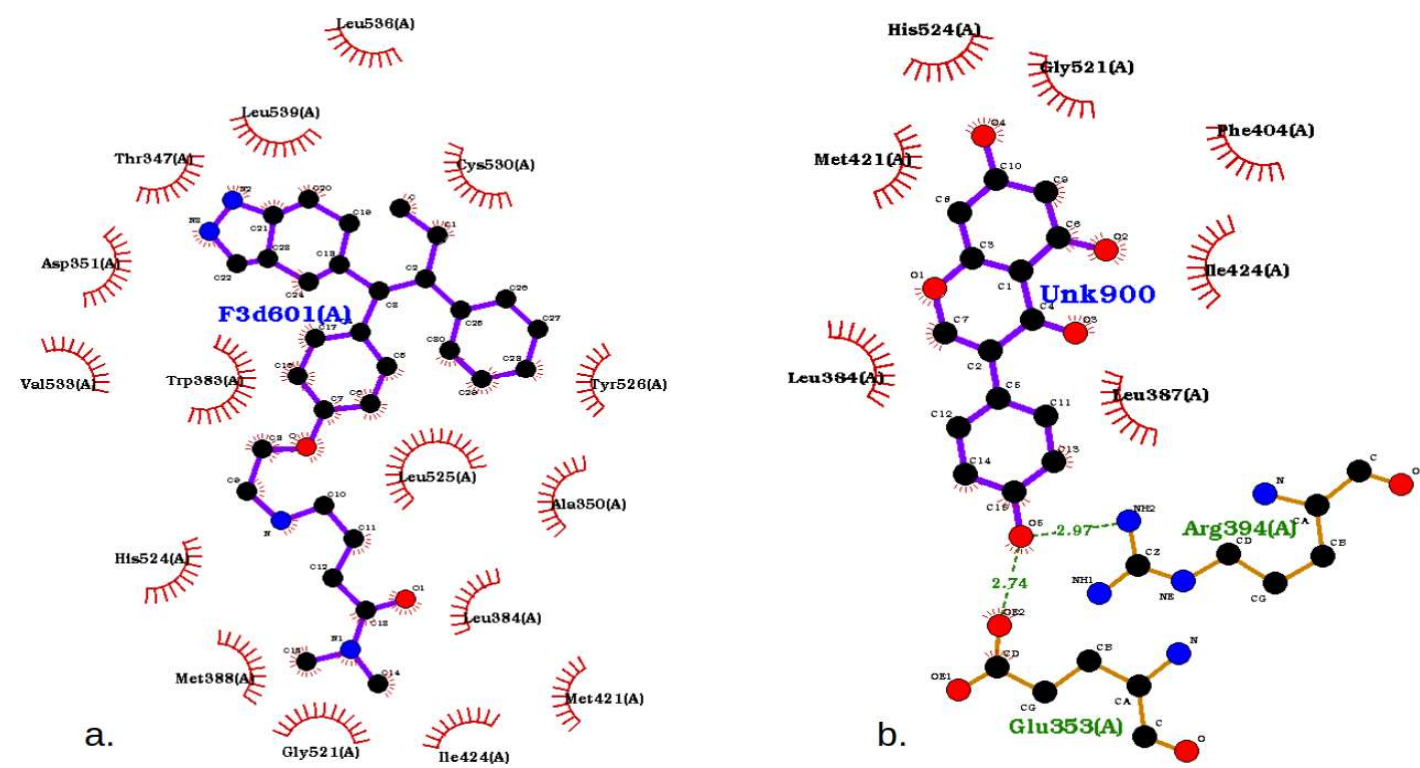

Figure 3.1.1: ((a) ERA-Chain-A in complex with 4-[(2-\{4-[(1E)-1-(1H-indazol-5-yl)-2-phenylbut-1 -en-1yl]phenoxy ethyl)amino]-N,N-dimethylbutanamide; (b) ERA-Chain-A in complex with Genistein) 


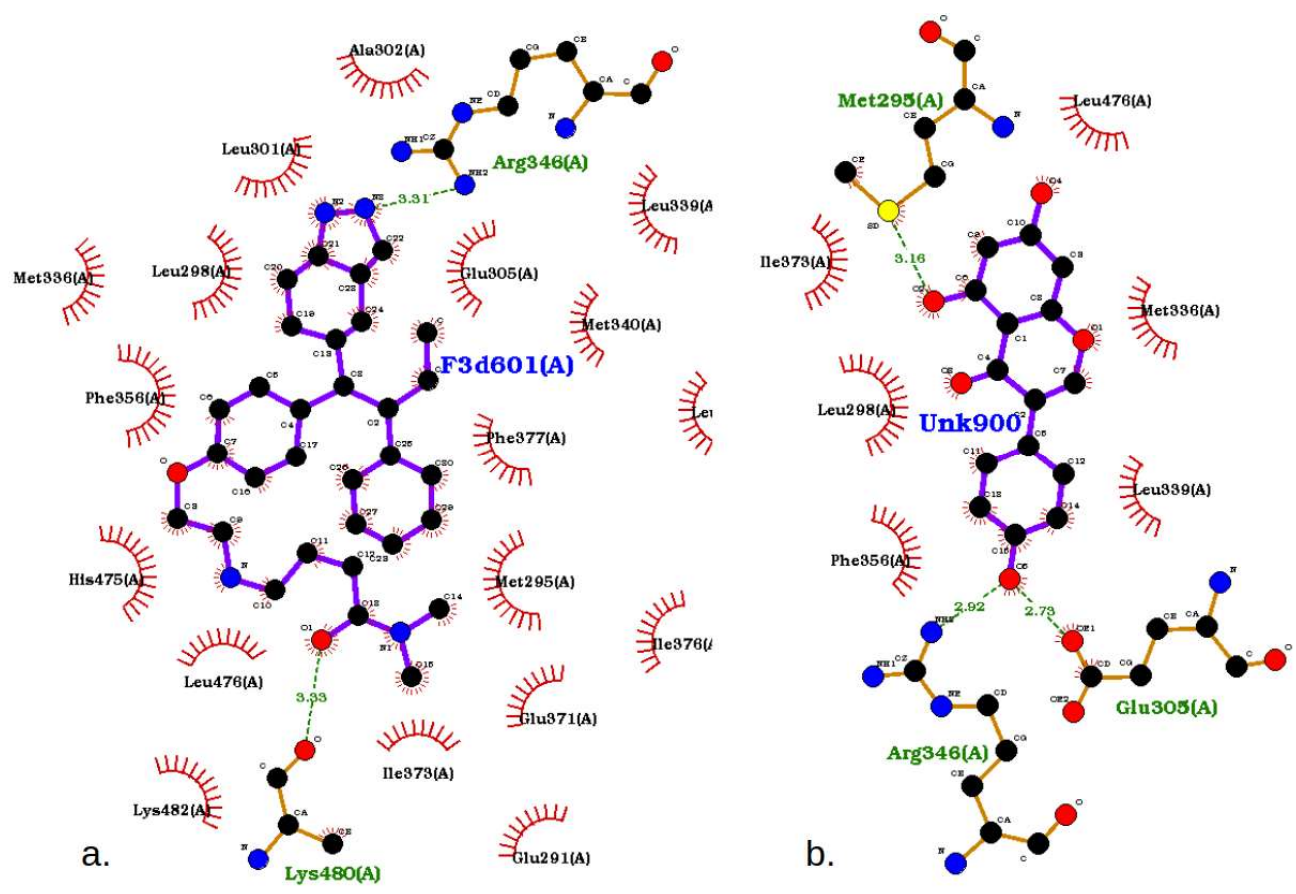

Figure 3.1.2 ((a) ERB-Chain-A in complex with (R,R)-5,11-cis-diethyl-5,6,11,12-tetrahydro- chrysene-2,8-diol; (b) ERB-Chain-A in complex with Genistein)

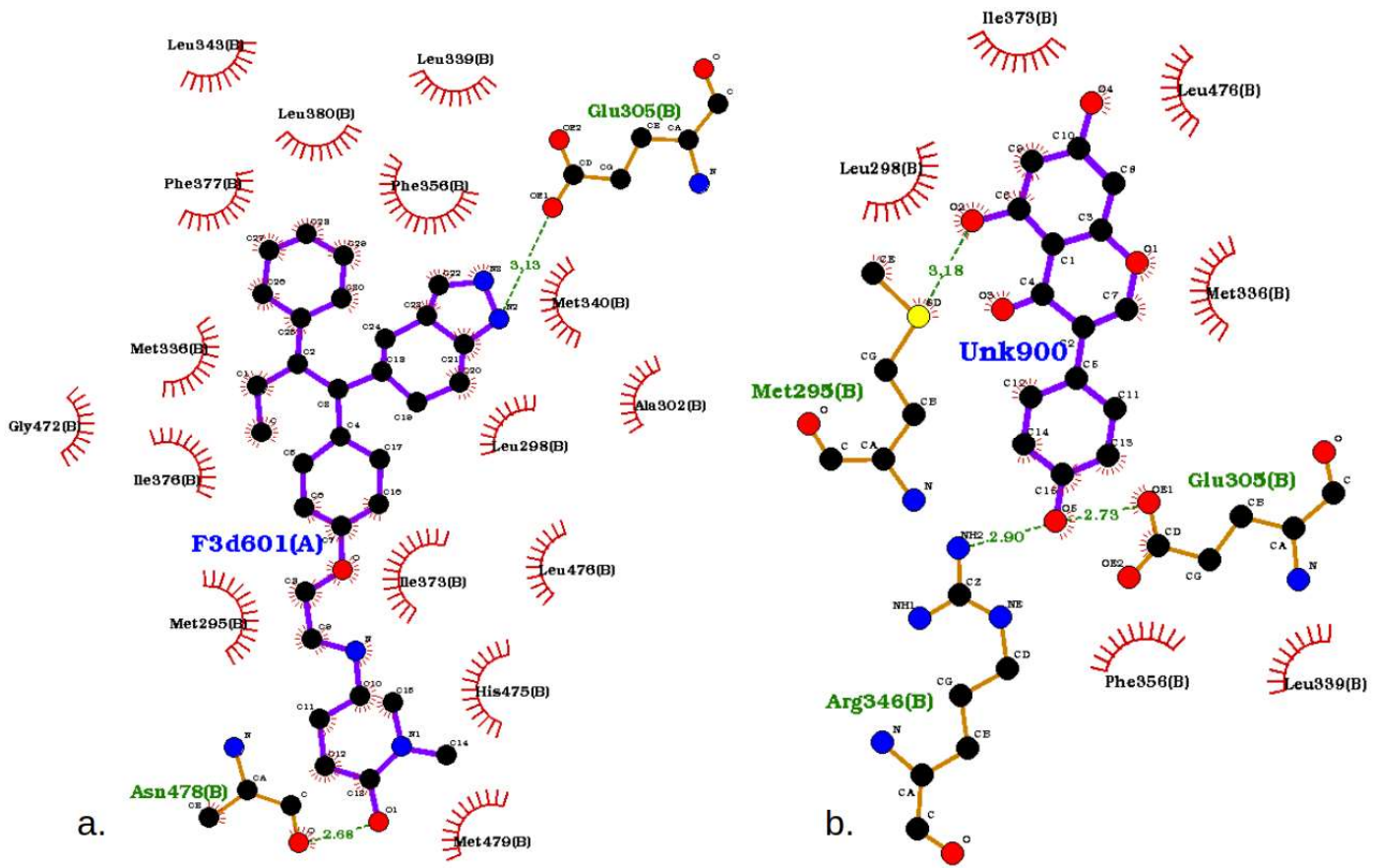

Figure 3.1.3: ((a) ERB-Chain-B in complex with (R,R)-5,11-cis-diethyl-5,6,11,12-tetrahydro- chrysene-2,8-diol; (b) ERB-Chain-B in complex with Genistein) 


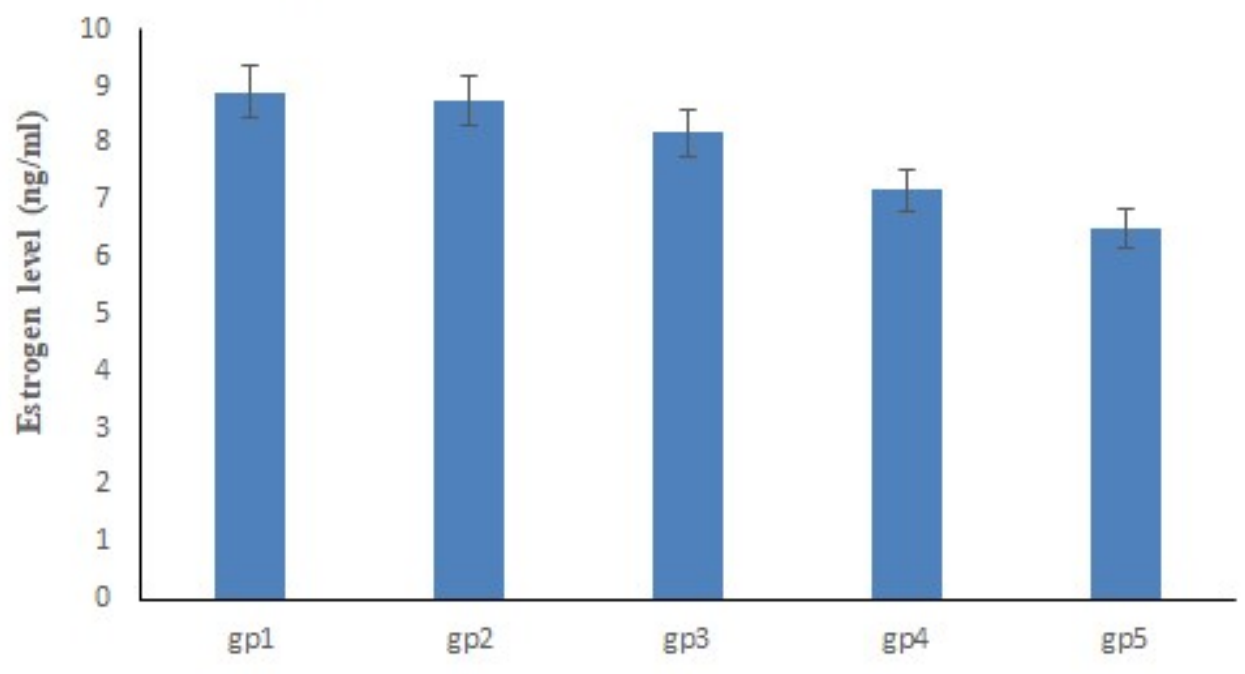

Figure 3.2.1: Comparision of circulating Estrogen levels (ng/ml) in Group 1(negative control), Group 2 (Vehicle), Group 3( Genistein -10 mg/kg), Group $4(20 \mathrm{mg} / \mathrm{kg})$ and Group $5(30 \mathrm{mg} / \mathrm{kg})$ after 15 days

\section{DISCCUSION}

Genistein showed better docking affinity (More Negative Docking Score) as compared to the already known antagonist in computational analysis. This confirms the antagonist nature of Genistein against the ERA and ERB. In order to evaluate its antifertility effects, the compound was administered to female wistar rats for 15 days and the blood sample was collected after the last treatment on $16^{\text {th }}$ day for hormone analysis through ELISA. The results depict that the level of estrogen was low in $3^{\text {rd }}, 4^{\text {th }}$ and $5^{\text {th }}$ groups $(10 \mathrm{mg} / \mathrm{kg}, 20$ $\mathrm{mg} / \mathrm{kg}$ and $30 \mathrm{mg} / \mathrm{kg}$, Genistein administered) as compared to all other groups (control, vehicle). Imbalance in the hormones leads to irregularity in the ovarian functions and duration of the estrus cycle [13-15], which indicates an availability of the matured secondary follicles Graafian follicles). Therefore, ovulation may be hindered or inhibited.

The essential role in the regulation of ovarian function is controlled by the hypothalamus- pitutary- gonadal axis. Functioning in a coordinated way with suitable signals provided by ovary through pituitary gland is responsible for the production of gonadotrophins (LH and FSH). However, administration of the Genistein to the female rats showed a remarkable decrease in the level of estradiol hormones. Estradiol is the most potent naturally occurring ovarian and placental estrogen in mammals. It prepares the uterus for implantation of the fertilized ovum and promotes the maturation and maintenance of the female accessory reproductive organs and secondary sexual characters. Plants with estrogenic activity can directly affect pituitary action by 
modulating $\mathrm{LH}$ and $\mathrm{FSH}$, decreasing secretion of these hormones, and blocking ovulation [16]. Thus, decreased serum concentration of estradiol observed in the group may be attributed to a decreased aromatase activity or substrate supplementation during estrogen synthesis [17]. Hence, such decreased in estradiol levels may hinder ovulation, preparation of the reproductive tract for zygote implantation, and the subsequent maintenance of pregnancy state [17].

\section{CONCLUSION}

The present study shows that Genistein has antagonist effects validated through insilico and in-vivo study both. The decreased level of estrogen led to interrupt the ovulation process in female rats. Further study needs to be done to evaluate level of other gonadotropins to support this finding.

\section{ACKNOWLEDGMENT}

We would like to take this opportunity to thank Amity Institute of Biotechnology (Amity University Uttar Pradesh, Noida) for providing us the infrastructure and Amity Institute of Pharmacology (Amity University Uttar Pradesh, Noida) for helping us with the CPCSEA approval and providing us the animal facility.

\section{REFERENCES}

[1] Kaur R, Sharma A, Kumar R and Kharb R: Rising Trends towards Herbal Contraceptives. Journal of
Natural Products and Plant Resour 2011; 1(4): 5-12

[2] Pathak AK, Mallurwar VR, Kondalkar AK and Soni S: A Review of Plants with Anti-Fertility Activity. Nig J Nat Prod and Med 2005; 09: 4-10.

[3] Shukla, A., Jamwal, R. \& Bala, K. (2017). Adverse effect of combined oral contraceptive pills. Asian J Pharma \& Clin Res, 10, 17-21.

[4] Rahaman NS, Azahari B, Effect of calcium hydrofiller loading on the properties on Bannana stem handsheet. Bioresources. 2012; 7(3): 4321.

[5] Kamath JV, Rana AC. Antifertility activity of the leaves of Plumbagoz eylanica L. in female albino rats. Indian J. Pharm Educ Res. 2010; 44(1): 49-55

[6] Hyacinth AA, Nwocha UC. Antifertility activity of aqueous ethanolic extract of Hymenocardia acida stem bark in female rats. Iran J Reprod Med. 2011; 9(3): 217-22.

[7] Kim H, Peterson TG and Barnes S: Mechanisms of action of the soy isoflavonegenistein: emerging role for its effects via transforming growth factor $\beta$ signaling pathways. Am J ClinNutr. 1998; 68(6 Suppl.): $1418 \mathrm{~S}-25 \mathrm{~S}$ 
[8] Berman HM, Westbrook J, Feng Z, et al. The Protein Data Bank. Nucleic Acids Res. 2000; 28(1): 235-242.

[9] Kim, S., Thiessen, P. A., Bolton, E. E., Chen, J., Fu, G., Gindulyte, A., Han, L., He, J., He, S., Shoemaker, B. A., Wang, J., Yu, B., Zhang, J., \& Bryant, S. H. (2016). PubChem Substance and Compound databases. Nucleic acids research, 44(D1), D1202-D1213.

[10] P. Srivastava, R. Pal and G. Misra, "Comparative modelling and virtual screening to discover potential competitive inhibitors targeting the 30s ribosomal subunit S2 and S9 in Acinetobacter baumannii," 2018 International Conference on Bioinformatics and Systems Biology (BSB), Allahabad, India, 2018, pp. 40-43,

[11] Tyagi, S., Saxena, S., Srivastava, P. et al. Screening the binding potential of quercetin with parallel, antiparallel and mixed Gquadruplexes of human telomere and cancer protooncogenes using molecular docking approach. SN Appl. Sci. 2, 490 (2020).

[12] Laskowski RA, Swindells MB. LigPlot+: multiple ligand-protein interaction diagrams for drug discovery. J ChemInf Model. 2011; 51(10): 2778-2786.

[13] Guraya SS. Fundamentals and Biomedical Implications. New Delhi: Narosa Publishing House; 1998. p. 10.

[14] Prakash AO, Mathur R. Studies on oestrous cycle of albino rats: Response to Embelia ribes extracts. Planta Med. 1979; 36(6): $131-41$

[15] Circosta C, Sanogo R, Occhiuto F. Effects of Calotropis procera on oestrous cycle and on oestrogenic functionality in rats. Farmaco. 2001; 56: 373.

[16] Brinker F. Inhibition of endocrine function by botanical agents, ant gonadotropic activity. $\mathrm{Br} \quad \mathrm{J}$ Phytother. 1997; 4: 123-45.

[17] Hsia SM, Yeh CL, Kuo YH, Wang PS, Chiang W. Effects of Adlay (Coixlachryma-jobi L. var. mayuen Stapf.) hull extracts on the secretion of progesterone and estradiol in vivo and in vitro. ExpBiol Med. 2007; 232(9): 118194. 